Gijsbert Wieringa, Josep Queraltó, Evgenija Homšak*, Nuthar Jassam, Etienne Cavalier, Dobrin Svinarov, Jasna L Krleža, Spyroula Christou, Richard Pikner, Trine Rennebod Larsen, Karel Tomberg, Anna Linko-Parvinen, Vincent Sapin, Hannsjorg Baum, Christos Kroupis, Zsuzsa Bagoly, Sean Costelloe, Laura Sciacovelli, Janis Stasulans, Dalius Vitkus, Danielle Meunier, Bogdan Solnica, Henrique Reguengo, Cristina Mambet, Gustav Kovac, Blaž Krhin, Mats Ohlson, Gerald Buhagiar and Ana-Maria Simundic

\title{
A proposed Common Training Framework for Specialists in Laboratory Medicine under EU Directive 2013/55/EC (The Recognition of Professional Qualifications)
}

https://doi.org/10.1515/cclm-2020-1504

Received October 14, 2020; accepted October 15, 2020;

published online November 30, 2020

\begin{abstract}
European Union (EU) Directive 2013/55/EC (The Recognition of Professional Qualifications) allows Member States to decide on a common set of minimum knowledge, skills and competences that are needed to pursue a given profession through a Common Training Framework. To be adopted the framework must combine the knowledge, skills and competences of at least one third of the Member
\end{abstract}

*Corresponding author: Evgenija Homšak, European Federation of Clinical Chemistry and Laboratory Medicine, Via Carlo Farini 81, 20159 Milan, Italy, E-mail: eflm@eflm.eu

Gijsbert Wieringa, Nuthar Jassam and Ana-Maria Simundic, European Federation of Clinical Chemistry and Laboratory Medicine, Brussels/ Milan, Belgium/Italy

Josep Queraltó, Spanish Society for Clinical Biochemistry and Molecular Pathology, Madrid, Spain

Etienne Cavalier, Royal Belgian Society of Laboratory Medicine, Brussels, Belgium

Dobrin Svinarov, Bulgarian Society of Clinical Laboratory, Sofia,

Bulgaria

Jasna L Krleža, Croatian Society of Medical Biochemistry and

Laboratory Medicine, Zagreb, Croatia

Spyroula Christou, Greek Society of Clinical Chemistry and Clinical Biochemistry, Athens, Greece

Richard Pikner, Czech Society of Clinical Biochemistry, Prague, Czech Republic

Trine Rennebod Larsen, Danish Society of Clinical Chemistry, Horsens, Denmark

Karel Tomberg, Estonian Society of Laboratory Medicine, Tartu,

Estonia

Anna Linko-Parvinen, Finnish Society of Clinical Chemistry, Helsinki, Finland

Vincent Sapin, French Society of Clinical Biology, Paris, France Hannsjorg Baum, German Society of Clinical Chemistry and Laboratory Medicine, Bonn/Berlin, Germany
States. Professionals who have gained their qualifications under a Common Training Framework will be able to have these recognised automatically within the Union. The backbone of the European Federation of Clinical Chemistry and Laboratory Medicine's (EFLM) proposed Common Training Framework for non-medical Specialists in Laboratory Medicine is outlined here. It is based on an Equivalence of Standards in education, training, qualifications, knowledge, skills, competences and the professional conduct associated with specialist practice. In proposing the recognition of specialist practice EFLM

Christos Kroupis, Greek Society of Clinical Chemistry and Clinical Biochemistry, Athens, Greece

Zsuzsa Bagoly, Hungarian Society of Laboratory Medicine, Debrecen, Hungary

Sean Costelloe, Association of Clinical Biochemists in Ireland, Dublin, Ireland

Laura Sciacovelli, The Italian Society of Clinical Biochemistry and Clinical Molecular Biology, Milan, Italy

Janis Stasulans, Latvian Society of Laboratory Specialists, Riga, Latvia

Dalius Vitkus, Lithuanian Society of Laboratory Medicine, Vilnius, Lithuania

Danielle Meunier, Luxembourg Society of Clinical Biology, Luxembourg, Luxembourg

Bogdan Solnica, Polish Society for Laboratory Diagnostics, Warsaw, Poland

Henrique Reguengo, Portuguese Society of Clinical Chemistry, Genetics and Laboratory Medicine, Porto, Portugal

Cristina Mambet, Romanian Association of Laboratory Medicine, Bucharest, Romania

Gustav Kovac, Slovak Society of Clinical Biochemistry, Bratislava, Slovakia

Blaž Krhin, Slovenian Association for Clinical Chemistry and Laboratory Medicine, Ljublijana, Slovenia

Mats Ohlson, Swedish Society for Clinical Chemistry, Stockholm, Sweden

Gerald Buhagiar, Department of Pathology, Mater Dei Hospital, Valetta, Malta 
has identified 15 EU Member States able to meet Equivalence and in whom the profession and/or its training is regulated (an additional EU Commission requirement). The framework supports and contributes to the Directive's enabling goals for increasing professional mobility, safeguarding consumers and ensuring a more equitable distribution of skills and expertise across the Member States. It represents EFLM's position statement and provides a template for professional societies and/or competent authorities to engage with the EU Commission.

Keywords: Common Training Framework; Equivalence of Standards; EU Directive 2013/55/EC; Recognition of Professional Qualifications; Specialist in Laboratory Medicine.

\section{Setting the scene}

It has been estimated that up to $70 \%$ of all medical decisions are based on data and information provided by laboratory medicine [1, 2]. It is the speciality that underpins modern medicine's understanding of health and disease. Its disciplines include clinical chemistry/immunology, haematology/blood transfusion, microbiology/virology/ parasitology, reproductive medicine, and genetics. Its contributions include screening for the early detection of disease, differential diagnosis, monitoring, management and treatment of patients, and their prognostic assessment. This contribution continues to grow through research and development, technological advances, and the increasing knowledge and skills base of its specialist practitioners.

The estimated 30,000 specialists in laboratory medicine across the European Union (EU) include medical $(\sim 40 \%)$, scientific $(\sim 30 \%)$ and pharmacy $(\sim 30 \%)$ trained staff [3]. Whilst specialists with a medical background have long enjoyed automatic recognition of their qualifications during cross-border professional migration as one of seven "sectorial professions" identified in EU Directive $2005 / 36 / \mathrm{EU}$ [4] the same is not true for the $60 \%$ of scientific and pharmacy-trained specialists under the "general system". However, through its amendment of the 2005 directive, Directive 2013/55/EU (The Recognition of Professional Qualifications) [5] the European Union:

- Provides opportunities for the mutual recognition of qualifications for the estimated 600 professions in the "general system" which in turn,

- Helps catalyse a more rapid and equitable distribution of human resource and services across the Union,

- Supports individuals seeking unhindered professional migration across EU borders,
- Identifies unique professional contributions that in turn can help obviate the need for "compensation measures" in which Member States impose, for example, retraining, new qualifications, aptitude tests, and adaptation periods on each others' professionals which may needlessly delay and deter migration.

Recognising that safeguards need to be in place to ensure the health and safety of consumers (for example, patients in the case of healthcare) is protected when professionals migrate to a host/receiving state the 2013 Professional Qualifications Directive allows Member States to decide on a common set of minimum knowledge, skills and competences that are needed to pursue a given profession through a Common Training Framework. To be adopted the framework must combine the knowledge, skills and competences of at least one third of the Member States. Professionals who have gained their qualifications under a Common Training Framework will be able to have these recognised automatically without further 'compensation measures' being imposed.

Proposing the recognition of specialist practitioners in laboratory medicine is commensurate with the European Federation of Clinical Chemistry and Laboratory Medicine's (EFLM) role and contribution in ensuring equitable, high quality, safe services for patients across the European Union's single market. In 1998, EFLM's forerunner organisation, the European Communities Confederation of Clinical Chemistry and Laboratory Medicine (EC4) established an Equivalence of Standards amongst the EU Member States based on education, training, qualifications, continuous professional development and professional conduct that it considered commensurate with the role of a European Specialist in Laboratory Medicine (EuSpLM) [6]. Individuals able to meet the standards are invited to join EFLM's Register of specialists [7]. The Equivalence standards together with the expected knowledge, skills and competencies for practicing at specialist level form the backbone of a proposed Common Training Framework which is outlined here. In setting the scene for the proposed framework an overview is first provided of specialists' unique contributions and their demographic profile in relation to further stipulations laid down by the 2013 Professional Qualifications Directive for example on regulation status and adoption of professional titles. The proposed Common Training Framework represents EFLM's position statement and offers the EU Member States a template for submission to the EU Commission. 


\section{The contribution of specialists in laboratory medicine to better health and best care}

\subsection{Roles and responsibilities}

Whilst the scope of practice at specialist level varies across the EU Member States the overlap is considerable such that common roles and responsibilities can be drawn out as follows:

- Provision of clinical and scientific leadership to direct and determine the scope and organisation of laboratory medicine services that are appropriate for local populations

- Working from an extensive, up to date knowledge and evidence base to ensure best practice

- Ability to work in a clinical environment to guide diagnostic testing and interpretation of results that aid in the screening of healthy populations, differential diagnosis of disease in patients, their appropriate treatment and management, and assessment of their prognosis.

- Leading and supporting research and development: innovating and implementing new technologies; initiating, conducting and evaluating clinical research; ensuring appropriate knowledge management

- Responsibilities for patient safety through participation and/or delivering quality assurance programmes, undertaking continuous audit and evaluation, understanding of ethical, legal and governance considerations

- Participation and/or leading teaching, education and training programmes

- Providing the clinical leadership that focuses on patients' needs and contributes to the evolution of health and healthcare services.

\subsection{The context of their contributions}

Knowledge, skills and competencies arm the specialist to provide solutions to ever changing demands. In part these demands are predicated by individual member state priorities but, increasingly, common themes emerge in the provision of healthcare across the community. Ongoing changes which require specialists' responses include:

a) Greater clinical governance expectations for evidencebased protocol driven care in the application of diagnostic tests, increasingly the appropriate application of Point of Care Testing in environments beyond the laboratory. b) The appropriate application of evolving artificial intelligence-driven digital technology and e-healthcare solutions that catalyse service reconfigurations and allow more effective use of resources.

c) A shift from voluntary to mandatory accreditation that places new expectations and standards to be met in laboratory management, support for human resource, premises/environment, technology/ information systems, and support for pre-and post-analytical phases.

d) A shift in funding priorities to improving public health as a means of reducing later, more costly hospital admissions that calls for new ways of working beyond the laboratory.

e) Expectations for professionals and professional practice to be appropriately registered and/or regulated to protect public and patients' interests and safety.

\section{The demographics of the profession}

Information provided by 26 national societies who are members of EFLM indicate that pharmacists and scientists are the majority specialist practitioners in $15 \mathrm{EU}$ Member States. Medical staff predominate in Austria, Belgium, Bulgaria, Denmark, Germany, Greece, Hungary, Ireland, Latvia, Malta and Sweden. Whilst pharmacists predominate in France, Portugal and Spain, scientists predominate in Croatia, Cyprus, Czech Republic, Estonia, Finland, Italy, Lithuania, Netherlands, Poland, Romania, Slovenia and Slovak Republic. There are reportedly no non-medical specialists practitioners in Malta and Austria. In collating the demographic information no response was received from Luxembourg.

The scope of non-medical practice is outlined in Table 1 , the unique role that distinguishes non-medical specialists from their medical colleagues in many Member States is the latter's provision of direct clinical care. It is estimated that over $80 \%$ of practitioners working in the Union at specialist level are able to meet the polyvalent scope of practice in clinical chemistry, haematology, and microbiology [3] set by EFLM's Equivalence of Standards.

Table 2 highlights that EFLM's Equivalence of Standards can be met in 19 of the EU's 27 Member States. In 15 (53\% of EU Member States) of these the profession or specialist training is regulated at government level, a prerequisite to proposing a Common Training Framework. The table also highlights the professional titles that would benefit from automatic recognition under the Professional Qualifications Directive on adoption of a Common Training Framework. The diversity of professional titles reflects a 
Table 1: Fields of non-medical specialist practice in laboratory medicine across EU member states.

\begin{tabular}{|c|c|c|c|c|c|c|}
\hline & Biochemistry & Endocrinology & Immunology & Haematology & Blood transfusion & Microbiology \\
\hline Austria & $\mathrm{N} / \mathrm{A}$ & $\mathrm{N} / \mathrm{A}$ & $\mathrm{N} / \mathrm{A}$ & $\mathrm{N} / \mathrm{A}$ & $\mathrm{N} / \mathrm{A}$ & $\mathrm{N} / \mathrm{A}$ \\
\hline Belgium & Yes & Yes & Yes & Yes & Yes & Yes \\
\hline Bulgaria & Yes & Yes & Yes & Partial & No & No \\
\hline Croatia & Yes & Yes & Yes & Yes & Partial & No \\
\hline Cyprus & Yes & Yes & Yes & Yes & Partial & Yes \\
\hline Czech Republic & Yes & No & Yes & Yes & Yes & Yes \\
\hline Denmark & Yes & Yes & Yes & Yes & No & No \\
\hline Estonia & Yes & Yes & Yes & Yes & Yes & Yes \\
\hline Finland & Yes & Yes & Partial & Yes & Partial & Partial \\
\hline France & Yes & Yes & Yes & Yes & Yes & Yes \\
\hline Germany & Yes & Yes & Yes & Yes & No & No \\
\hline Greece & Yes & Yes & Yes & Yes & Yes & No \\
\hline Hungary & Yes & Yes & Partial & Yes & No & No \\
\hline Ireland & Yes & Yes & No & No & No & No \\
\hline Italy & Yes & Yes & Yes & Yes & No & Yes \\
\hline Latvia & Yes & Yes & Yes & Yes & Yes & Yes \\
\hline Lithuania & Yes & Yes & Yes & Yes & Yes & Yes \\
\hline \multicolumn{7}{|l|}{ Luxembourg } \\
\hline Malta & $\mathrm{N} / \mathrm{A}$ & $\mathrm{N} / \mathrm{A}$ & $\mathrm{N} / \mathrm{A}$ & $\mathrm{N} / \mathrm{A}$ & $\mathrm{N} / \mathrm{A}$ & $\mathrm{N} / \mathrm{A}$ \\
\hline Netherlands & Yes & Yes & Yes & Yes & Yes & No \\
\hline Poland & Yes & Yes & Yes & Yes & Partial & No \\
\hline Portugal & Yes & Yes & Yes & Yes & Partial & Yes \\
\hline Romania & Yes & Yes & Yes & Yes & Yes & Yes \\
\hline Slovak Republic & Yes & Yes & Yes & Yes & Partial & Yes \\
\hline Slovenia & Yes & Yes & Yes & Yes & Partial & Partial \\
\hline Spain & Yes & Yes & No & Yes & No & No \\
\hline Sweden & Yes & Yes & Partial & Yes & Yes & Yes \\
\hline
\end{tabular}

profession that is identified and/or regulated at Member State level rather than at EU level albeit with overlapping qualifications frameworks that meet requirements of the European Qualifications Framework. In support of a unified approach to proposing a Common Training Framework EFLM's affiliated societies adopted the term 'Specialist in Laboratory Medicine' as the unifying descriptor of specialist practice amongst medical, scientific and pharmacy trained professionals in 2012 [8]. Whilst not intended as a precursor to identifying a newly regulated profession at EU Level the name forms the central descriptor within a Common Training Framework.

\section{The shape of a Common Training Framework}

\subsection{An equivalence of standards of practice amongst the EU member states}

EFLM's Equivalence of Standards distinguish the specialist practitioner in laboratory medicine from the non-specialist. Based on the principles of the 1999 Bologna process [9] the key elements of the standards:
- Defines 9 (preferably 10) years as minimum training period with a Master of Science (MSc or equivalent) qualification after an initial 4 to 5 -year academic period followed by an EFLM-approved exit qualification/ certificate after a further 4 years vocational training.

- Includes expectations for education and training to follow the EFLM syllabus [10] that also identifies the competences required to assure patients that they receive safe and high quality care.

- Requires specialists to be included in a professional register (if available) in their home country and to maintain their competence and knowledge base through participation in Continuous Professional Development activities

Based on the requirements in which the profession and/or its training is regulated the training content should include:

- General chemistry of at least 35\%.

- General chemistry plus haematology of at least $65 \%$.

- Flexibility as to the remaining 35\%, including general chemistry, haematology, microbiology, genetics and In Vitro Fertilisation in a proportion consistent with the requirements in the country of destination, consisting 
Table 2: The professional profile of non-medical specialists in Laboratory Medicine across the European Union. Member States able to meet expectations of EFLM's proposed Common Training Framework are highlighted in green.

\begin{tabular}{|c|c|c|c|c|}
\hline & $\begin{array}{l}\text { Predominant } \\
\text { non-medical } \\
\text { specialist } \\
\text { practitioner }\end{array}$ & $\begin{array}{l}\text { Meets EFLM } \\
\text { equivalence of } \\
\text { standards }\end{array}$ & $\begin{array}{l}\text { Professional regula- } \\
\text { tion and/or } \\
\text { regulated training in } \\
\text { place }\end{array}$ & Professional title \\
\hline Austria & Not applicable & & & \\
\hline Belgium & Pharmacist & Yes & Yes & Pharmacien biologiste (Pharmacist biologist) \\
\hline Bulgaria & Scientist & Yes & Yes & Специалист по клинична химия (Specialist in clinical chemistry) \\
\hline Croatia & Scientist & Yes & Yes & $\begin{array}{l}\text { Specijalist medicinske biokemije i laboratorijske medicine } \\
\text { (Specialist in medical biochemistry and laboratory medicine) }\end{array}$ \\
\hline Cyprus & Scientist & Yes & Yes & 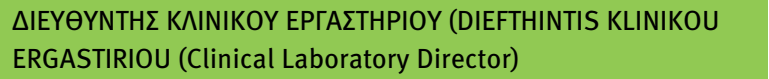 \\
\hline $\begin{array}{l}\text { Czech } \\
\text { Republic }\end{array}$ & Scientist & Yes & Yes & $\begin{array}{l}\text { Bioanalytik pro klinickou biochemii (Bioanalyst for Clinical } \\
\text { Chemistry) }\end{array}$ \\
\hline $\begin{array}{l}\text { Denmark } \\
\text { Estonia }\end{array}$ & $\begin{array}{l}\text { Scientist } \\
\text { Scientist }\end{array}$ & $\begin{array}{l}\text { Yes } \\
\text { No }\end{array}$ & $\begin{array}{l}\text { No } \\
\text { No }\end{array}$ & $\begin{array}{l}\text { Biokemiker (Biochemist) } \\
\text { Laborispetsialist (Laboratory specialist) }\end{array}$ \\
\hline $\begin{array}{l}\text { Finland } \\
\text { France }\end{array}$ & $\begin{array}{l}\text { Scientist } \\
\text { Pharmacist }\end{array}$ & $\begin{array}{l}\text { Yes } \\
\text { Yes }\end{array}$ & $\begin{array}{l}\text { Yes } \\
\text { Yes }\end{array}$ & $\begin{array}{l}\text { Sairaalakemisti (Clinical biochemist) } \\
\text { Pharmacien biologiste (Pharmacist biologist) }\end{array}$ \\
\hline $\begin{array}{l}\text { Germany } \\
\text { Greece }\end{array}$ & $\begin{array}{l}\text { Scientist } \\
\text { Scientist }\end{array}$ & $\begin{array}{l}\text { Yes } \\
\text { Yes }\end{array}$ & $\begin{array}{l}\text { No } \\
\text { No }\end{array}$ & 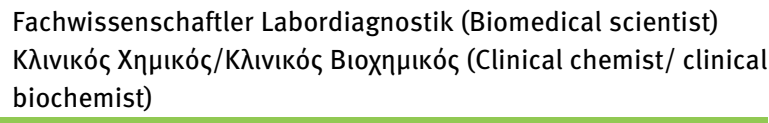 \\
\hline Hungary & Scientist & Yes & Yes & Klinikai biokémikus (Clinical biochemist) \\
\hline Ireland & Scientist & Yes & No & Clinical biochemist \\
\hline Italy & Scientist & Yes & Yes & $\begin{array}{l}\text { Specialista in Patologia clinica e Biochimica clinica (Specialist in } \\
\text { Clinical Pathology and Clinical Biochemistry) }\end{array}$ \\
\hline Latvia & Scientist & No & Yes & Laboratorijas specialists (Laboratory Specialist) \\
\hline Lithuania & Scientist & Yes & Yes & Medicinos biologas (Medical biologist) \\
\hline Luxembourg & $\begin{array}{l}\text { Pharmacist } \\
\text { Not applicable }\end{array}$ & & & \\
\hline Netherlands & Scientist & Yes & No & Specialist klinische chemie (Specialist in clinical chemistry) \\
\hline $\begin{array}{l}\text { Poland } \\
\text { Portugal }\end{array}$ & $\begin{array}{l}\text { Scientist } \\
\text { Pharmacist }\end{array}$ & $\begin{array}{l}\text { Yes } \\
\text { Yes }\end{array}$ & $\begin{array}{l}\text { Yes } \\
\text { Yes }\end{array}$ & $\begin{array}{l}\text { Specialist in Laboratory Diagnostics } \\
\text { Especialista em Analises Clinicas (Clinical Analysis Specialist) }\end{array}$ \\
\hline Romania & Scientist & Yes & No & $\begin{array}{l}\text { Biochimist, Biolog sau Chimist in sistemul sanitar (Biochemist, } \\
\text { Biologist or Chemist in the health system) }\end{array}$ \\
\hline $\begin{array}{l}\text { Slovak } \\
\text { Republic }\end{array}$ & Scientist & Yes & Yes & $\begin{array}{l}\text { Laboratórny Diagnostik Specialista (Specialist in Laboratory } \\
\text { Diagnostics) }\end{array}$ \\
\hline Slovenia & Scientist & Yes & Yes & $\begin{array}{l}\text { Specialist medicinske biokemije (Specialist in Medical } \\
\text { Biochemistry) }\end{array}$ \\
\hline Spain & Pharmacist & Yes & Yes & $\begin{array}{l}\text { Especialista (Specialist) Médico, Farmacéutico, Químico o } \\
\text { Biólogo (Medical, Pharmaceutical, Chemist or Biologist) }\end{array}$ \\
\hline Sweden & Scientist & No & No & Sjuknuskemist (Clinical biochemist) \\
\hline
\end{tabular}

of work experience, accredited courses, relevant exams of the national training programs, traineeships.

The elements of training in the main fields of laboratory include:

- General chemistry: general biochemistry and pathophysiology, endocrinology, oncology, cardiovascular, metabolic, renal and other biomarkers, humoral immunology, therapeutic drug monitoring and toxicology.
- Haematology: cytometry, haemostasis, cellular immunology and transfusion medicine.

- Microbiology includes bacteriology, mycology, virology, parasitology and emerging diseases that affect public health.

In addition, elements of sub-specialisation may include:

- Genetics includes molecular diagnostics

- IVF includes fertility testing, semen investigation, semen preparation and in vitro fertilization. 


\subsection{The expected base of knowledge, skills and competences}

Throughout training and education, the objective is to develop the knowledge, skills, competence, attitudes and behaviours consistent with specialist level clinical, scientific and professional practise. The key elements of the 2018 EFLM syllabus [10] include:

- Generic knowledge, skills and competences

- Basic knowledge requirements

- Indications for laboratory medicine procedures

- Influence of collection and storage of specimens

- Analytical principles and techniques;

- Reference methodology

- Evaluation and assessment

- Case related medical evaluation of laboratory tests

- Clinical training

- Specialist knowledge within each discipline.

- General chemistry

- Haematology

- Microbiology

- Genetics, genomics and cytogenetics

- In vitro fertilisation

- Skills and competences required to carry out research, development and audit.

- Leadership skills and competences.

- Laboratory direction and leadership

- Laboratory organisation and management

- Quality assurance

- Education/training/continuous professional development

- Laboratory health and safety, management of waste

- Legal, ethical and governance considerations

- Professional practice and soft skills

\subsection{An expected code of conduct [11]}

The code of conduct behoves specialists to conduct themselves in a manner that does not bring into disrepute the discipline and the profession of Clinical Chemistry and

Laboratory Medicine. They shall value integrity, impartiality and respect for persons and evidence and shall seek to establish the highest standards of quality and ethics in their work. Because of their concern for valid evidence, they shall ensure that research is carried out in keeping with the highest standards of scientific integrity. Taking account of their obligations under the law, they shall hold the interest and welfare of patients and those in receipt of their services to be paramount at all times and ensure that the interests of participants in research are safeguarded. All registrants agree to abide by this Code of Conduct. They are also obliged to comply with the Codes of Conduct of their appropriate national registration body and national societies, where appropriate. If a specialist is subject to disciplinary sanction (e.g. suspension, removal from their national register), EFLM applies the same outcome in relation to the EFLM Register.

\section{Discussion}

In line with three key conditions of the Professional Qualifications Directive that need to be fulfilled for being subject to a Common Training Framework, non-medical specialists:

a) can be identified as a regulated profession and/or a profession whose training is regulated in at least one third (33\%) of the EU member states,

b) are not already subject to automatic recognition as a sectorial profession nor to another level Common Training Framework

c) would possibly have their professional mobility enhanced with the adoption of a Common Training Framework

The proposed Common Training Framework builds on EU guidance [12] for a 'bottom up' approach in which professional organisations or competent authorities from at least one third of the Member States may submit suggestions for a framework to the Commission. Such an approach is meant to ensure that proposals respond to real needs felt by the profession and benefit from the in-depth knowledge and understanding of the area concerned. At the time of writing 19 of EFLM's affiliated national societies in the EU highlight their country's ability to meet the federation's Equivalence of Standards, the expected level of knowledge, skill and competency, and the code of conduct. Amongst these 19 Member States 15 (53\%) are also able to meet the requirements of the proposed Common Training Framework in that the profession and/or training is regulated and their national qualification frameworks are formally linked (referenced) to the European Qualifications Framework for lifelong learning [13], a further EU Commission requirement for submission of the framework.

In progressing a submission the opportunity arises for the EU Commission to adopt a Common Training Framework by "delegated act" (a delegation granted in the text 
of an EU law such as the Professional Qualifications Directive that allows consideration of a suggested framework by delegated authorities within the Commission) followed by an implementing act to list the national professional qualifications and national titles that benefit from automatic recognition under the adopted Common Training Framework [14]. However, whilst laboratory medicine has established key building blocks for the mutual recognition of its specialist practitioners' qualifications a current 'a priori' challenge across the EU is determining the 'proportionality' of the professional regulatory frameworks held within the individual member states which may have been built up and/or modified over many years [15]. The uneven scrutiny of the regulation of professions across the EU has been deemed to have a negative impact on the provision of services and the mobility of professionals in a single EU market - the need for a mutual evaluation exercise facilitated by the Commission was identified within EC Directive 2013/55/EC to ensure greater transparency and justification [16]. Within the exercise Member States provide a list of their regulated professions, the activities reserved for them and a justification of the need for regulation. The subsequent 2018 Proportionality Directive [17] supplements provisions within the 2013 Directive and now requires Member States to review existing regulations of professions or when proposing new ones.

\section{Conclusions}

Through the engagement of professional organisations 15 EU Member States have been identified as candidate signatories to a Common Training Framework for Specialists in Laboratory Medicine. Achieving recognition is an ongoing project in part dictated by external timelines and jurisdictions but crucially also by professional organisations and competent authorities who recognise the catalytic effect the Professional Qualifications Directive brings to harmonising the education and training that enhances patient safety when professionals migrate across country borders. Whilst Common Training Frameworks do not replace national programmes unless a Member State decides otherwise [5] it is of note that the EFLM syllabus has been adopted as the template for education and training in 19 Member States. Pending progress with achieving proportionate professional regulation and further guidance from the EU Commission the onus is on national societies and competent authorities to capitalise on opportunities to submit suggestions for a Common Training Framework as and when they arise. EFLM's proposed framework carries the support of more than one third of its professional organisations in the EU Member States. In turn the framework supports and contributes to the Directive's enabling goals for increasing professional mobility, enhancing patient safety and ensuring a more equitable distribution of skills and expertise across the Member States.

Acknowledgments: EFLM regrets the sad passing of our colleague Dr. Josep Maria Queralto during the preparation of this paper.

Research funding: None declared.

Author contributions: All authors have accepted responsibility for the entire content of this manuscript and approved its submission.

Competing interests: Authors state no conflict of interest.

\section{References}

1. Report of the review of NHS pathology services in England. https:// www.networks.nhs.uk/nhs-networks/peninsula-pathologynetwork/documents/CarterReviewPathologyReport.pdf.

2. Hallworth MJ. The ' $70 \%$ claim': what is the evidence base?. Ann Clin Biochem 2011;48:487-90.

3. Oosterhuis WP, Zerah S. Laboratory medicine in the European union. Clin Chem Lab Med 2015;53:5-14.

4. Directive 2005/36/EC of the European parliament and of the council of 7 september 2005 on the recognition of professional qualifications https://eur-lex.europa.eu/legal-content/EN/TXT/? uri=celex\%3A32005L0036.

5. Directive $2013 / 55 / E U$ of the European parliament and of the council of 20 november 2013 amending directive 2005/36/EC on the recognition of professional qualifications and regulation (EU) No $1024 / 2012$ on administrative cooperation through the internal market information system ('the IMI regulation') text with EEA relevance https://eur-lex.europa.eu/legal-content/EN/ALL/? uri $=$ celex\%3A32013L0055.

6. Jansen RTP. The EC4 Register of European clinical chemists and EC4 activities. Clin Chim Acta 2002;319:143-8.

7. Wieringa GE, Jassam N, Homsak E, Rako I, Racek J. The academy of the European federation of clinical chemistry and laboratory medicine and the European register of specialists in laboratory medicine: guide to the academy and the register, version 4-2020. Clin Chem Lab Med 2021;59:503-7.

8. Zerah S, McMurray J, Horvath AR. Our profession now has a European name: specialist in laboratory medicine. Biochem Med 2012;22:272-3.

9. The Bologna process and the European higher education area. https://ec.europa.eu/education/policies/higher-education/ bologna-process-and-european-higher-education-area_en. 
10. Jassam N, Lake J, Dabrowska M, Queralto J, Rizos D, Lichtinghagen R, et al. The European federation of clinical chemistry and laboratory medicine syllabus for postgraduate education and training for specialists in laboratory medicine: version $5-2018$. Clin Chem Lab Med 2018;56:1846-63.

11. McMurray J, Zerah S, Hallworth M, Koeller U, Blaton V, Tzatchev K, et al. The European register of specialists in clinical chemistry and laboratory medicine: code of conduct, version $2-2008$. Clin Chem Lab Med 2009;47:372-5.

12. European Commission. Common Training Frameworks expressions of interest and way forward. European Commission Grow 2015. D4/SW/pt Ares(2015) S 275275, 21st January.

13. The European qualifications framework https://www.cedefop. europa.eu/en/events-and-projects/projects/europeanqualifications-framework-eqf.

14. European Commission. Implementing and delegated acts https:// ec.europa.eu/info/law/law-making-process/adopting-eu-law/ implementing-and-delegated-acts_en\#implementing-acts.
15. Proposal for a Directive of the European Parliament and of the Council on a proportionality test before adoption of new regulation of professions. https://eur-lex.europa.eu/legalcontent/BG/ALL/?uri=CELEX:52016PC0822R(01).

16. European Commission Press release. Commissioner Michel Barnier welcomes the trilogue agreement on the modernisation of the professional qualifications directive. Memo [serial on the Internet]; 2013. Available from: http://europa.eu/rapid/pressrelease_MEMO-13-552_en. htmFee.

17. Directive (EU) $2018 / 958$ of the European Parliament and of the Council of 28 June 2018 on a proportionality test before adoption of new regulation of professions. https://eur-lex.europa.eu/eli/ $\operatorname{dir} / 2018 / 958 /$ oj.

Supplementary Material: The online version of this article offers supplementary material (https://doi.org/10.1515/cclm-2020-1504). 